\title{
Clinically relevant GSK-3 $\beta$ inhibitor 9-ING-41 is active as a single agent and in combination with other antitumor therapies in human renal cancer
}

\author{
TSUTOMU ANRAKU ${ }^{1}$, HIROO KUROKI ${ }^{1}$, AKIRA KAZAMA ${ }^{1}$, VLADIMIR BILIM ${ }^{1,2}$, MASAAKI TASAKI $^{1}$, \\ DANIEL SCHMITT $^{3}$, ANDREW MAZAR ${ }^{4}$, FRANCIS J. GILES ${ }^{3}$, ANDREY UGOLKOV ${ }^{3}$ and YOSHIHIKO TOMITA ${ }^{1}$ \\ ${ }^{1}$ Department of Urology, Division of Molecular Oncology, Graduate School of Medical and Dental Sciences, \\ Niigata University, Niigata 951-8510; ${ }^{2}$ Department of Urology, Kameda Daiichi Hospital, Niigata 950-0165, Japan; \\ ${ }^{3}$ Actuate Therapeutics, Fort Worth, TX 76107; ${ }^{4}$ Monopar Therapeutics, Wilmette, IL 60091, USA
}

Received July 8, 2019; Accepted November 14, 2019

DOI: $10.3892 / \mathrm{ijmm} .2019 .4427$

\begin{abstract}
Glycogen synthase kinase-3 (GSK-3), a serine/threonine kinase, is involved in a broad range of pathological processes including cancer. GSK-3 has two isoforms, GSK-3 $\alpha$ and GSK-3 $\beta$, and GSK-3 $\beta$ has been recognized as a therapeutic target for the development of new anticancer drugs. The present study aimed to investigate the antitumor effects of 9-ING-41, which is a maleimide-based ATP-competitive small molecule GSK-3 $\beta$ inhibitor active in patients with advanced cancer. In renal cancer cell lines, treatment with 9-ING-41 alone induced cell cycle arrest and apoptosis, and autophagy inhibitors increased the antitumor effects of 9-ING-41 when used in combination. Treatment with $9-\mathrm{ING}-41$ potentiated the antitumor effects of targeted therapeutics and increased the cytotoxic effects of cytokine-activated immune cells on renal cancer cell lines. These results provided a compelling rationale for the inclusion of patients with renal cancer in studies of $9-\mathrm{ING}-41$, both as a single agent and in combination with current standard therapies.
\end{abstract}

\section{Introduction}

In the US, there are $\sim 64,000$ new cases of renal cell carcinoma (RCC) and 14,000 RCC-related deaths each year (1). In the past decade, systemic therapy for metastatic RCC has notably improved, moving from the use of immunotherapeutic interferon $\alpha$ to a variety of targeted therapeutics, which include anti-angiogenic drugs targeting vascular endothelial growth factor and its receptors, mTOR inhibitors, receptor

Correspondence to: Professor Yoshihiko Tomita, Department of Urology, Division of Molecular Oncology, Graduate School of Medical and Dental Sciences, Niigata University, 1-757 Asahimachi-dori, Chuo Ward, Niigata, Niigata 951-8510, Japan

E-mail: ytomita@med.niigata-u.ac.jp

Key words: glycogen synthase kinase-3, renal cell carcinoma, apoptosis, cell cycle arrest, immune cells tyrosine kinase inhibitors and immune checkpoint inhibitors (2). Despite the progress in treatment options, metastatic RCC remains incurable with median progression-free survival ranging between 8 and 11 months for patients treated with sunitinib and pazopanib (3-5). Therefore, more effective drugs are needed to improve treatment outcomes for patients with metastatic RCC.

Glycogen synthase kinase-3 (GSK-3) is a multifunctional kinase involved in a broad range of pathological processes, including neurodegenerative diseases and cancer (6). GSK-3 is a serine/threonine protein kinase that phosphorylates and inactivates glycogen synthase (GS) (7). GSK-3 has two isoforms, GSK-3 $\alpha$ and GSK-3 $\beta$ (6). Despite their homology, GSK-3 $\alpha$ and GSK-3 $\beta$ are encoded by different genes, serve independent functions, and the loss of one is not compensated by the other (8). GSK-3 $\beta$ has been considered as a potential tumor suppressor as it phosphorylates and targets pro-oncogenic molecules including c-Jun (9), c-Myc (10), cyclin D1 (11) and $\beta$-catenin (12) for ubiquitin-dependent proteasomal degradation. However, over the past decade, GSK-3 $\beta$ has emerged as a therapeutic target in several different types of cancer (13), including renal cancer (14). The GSK-3 $\beta$ inhibitor 9-ING-41 has entered clinical trials in patients with advanced cancer (clinical trial no. NCT03678883). 9-ING-41 is a maleimide-based ATP-competitive small molecule GSK-3 $\beta$ inhibitor with high selectivity and low toxicity $(15,16)$. The antitumor activity of 9-ING-41 has been demonstrated in models of glioblastoma (17), neuroblastoma (18), breast (19), ovarian (15), pancreatic (16) and renal (20) cancer. The present study aimed to determine whether $9-\mathrm{ING}-41$ may potentiate the antitumor effects of chemotherapeutic drugs and targeted therapeutics and increase the cytotoxic effects of human immune cells in RCC cell lines.

\section{Materials and methods}

Cell culture and reagents. RCC cell lines ACHN and KRCY were obtained from the American Type Culture Collection. Caki-1 was obtained from Japanese Collection of Research Bioresources Cell Bank. KU19-20 was kindly provided 
by Dr Mototsugu Oya (Department of Urology, School of Medicine, Keio University, Tokyo, Japan). The cells were cultured in RPMI-1640 medium (Gibco; Thermo Fisher Scientific, Inc.) supplemented with 10\% FBS (Gibco; Thermo Fisher Scientific, Inc.), $1 \%$ MEM Non-Essential Amino Acids (Gibco; Thermo Fisher Scientific, Inc.), 1\% MEM sodium pyruvate solution $100 \mathrm{mM}$ (Gibco; Thermo Fisher Scientific, Inc.) and $90 \mu \mathrm{g} / \mathrm{ml} \mathrm{kanamycin} \mathrm{in} \mathrm{a} 37^{\circ} \mathrm{C}$ incubator containing $5 \% \mathrm{CO}_{2} .9-\mathrm{ING}-41$ was provided by Actuate Therapeutics, Inc. and used at 0.5-50 $\mu \mathrm{M}$. Sorafenib was obtained from ChemScence, LLC and used at 3-8 $\mu \mathrm{M}$. Sunitinib was obtained from Sigma-Aldrich; Merck KGaA and used at 1-4 $\mu \mathrm{M}$. Cabozantinib was obtained from LC Laboratories and used at 0.5-6 $\mu \mathrm{M}$. Pazopanib, chloroquine and bafilomycin were obtained from Cayman Chemical Company and used at 0.5-1, 8-30 and 1-10 $\mu \mathrm{M}$, respectively. Control cells were treated with an equal amount of DMSO. Mycoplasma testing was performed for all cell lines; if mycoplasma was positive, the cells were treated with MC-210 (DS Pharma Promo Co., Ltd.) at $0.5 \mu \mathrm{g} / \mathrm{ml}$ for two weeks, and the reagent was washed out for another one week at $37^{\circ} \mathrm{C}$ in an incubator.

Cell viability and proliferation assays. Cell viability was detected with a colorimetric CellTiter $96^{\circledR}$ AQueous One Solution Cell Proliferation assay (Promega Corporation), using a tetrazolium compound according to the manufacturer's instructions using ACHN, Caki-1, KRCY and KU19-20 cell lines. The cells were treated with $0.5-5 \mu \mathrm{M}$ 9-ING-41 during the assay, and cell viability was measured at $0,24,48,72$ and $96 \mathrm{~h}$ in $9-\mathrm{ING}-41$ monotherapy. In the combination treatment, 9-ING-41 was used at 0.5-4 $\mu \mathrm{M}$ during the assay, and cell viability was measured at 0 and $72 \mathrm{~h}$. For the estimation of cell proliferation, a 5-bromo-2-deoxyuridine (BrdU) Cell Proliferation Assay kit (EMD Millipore) was used according to the manufacturer's instructions using ACHN, Caki-1, KRCY and KU19-20 cell lines. The cells were treated with $0-25 \mu \mathrm{M}$ 9-ING-41. Both experiments were performed in three or four replicates using a flat-bottom 96-well plate (Corning, Inc.) and an iMark ${ }^{\mathrm{TM}}$ 96-well microplate reader (Bio-Rad Laboratories, Inc.). Absorbance was measured at $490 \mathrm{~nm}$ in the cell viability assay and at $450-595 \mathrm{~nm}$ in the cell proliferation assay. $\mathrm{GI}_{50}$, a concentration of the drug that inhibits the proliferation of cancer cells by $50 \%$, was calculated using GraphPad Prism 7 (GraphPad Software, Inc.).

Analysis of cell cycle and apoptosis. ACHN and KRCY cells were fixed in cold $70 \%$ ethanol for $30 \mathrm{~min}$. Propidium iodide (PI) staining of fixed cells was performed for cell cycle analysis and quantification of apoptosis (sub- $\mathrm{G}_{1}$ population) using FxCycle ${ }^{\mathrm{TM}}$ PI/RNase Staining Solution (Thermo Fisher Scientific, Inc.) according to the manufacturer's instructions. Stained cells were analyzed using BD Accuri ${ }^{\mathrm{TM}}$ C6 software and a BD Accuri ${ }^{\mathrm{TM}}$ C6 Flow Cytometer (BD Biosciences).

Western blotting. Subconfluent cell cultures were washed with cold PBS and lysed in lysis buffer (150 mM sodium chloride, $5 \mathrm{mMEDTA}, 1 \%$ Triton X-100, $100 \mathrm{mM}$ Tris- $\mathrm{HCl}$ and a protease inhibitor). Following clarification of the lysates by centrifugation at $15,000 \mathrm{xg}$ for $30 \mathrm{~min}$ at $4^{\circ} \mathrm{C}$, protein concentration was detected by the Bradford method, and $30 \mu \mathrm{g}$ of each protein was electrophoretically separated on a 10\% SDS-polyacrylamide gel and transblotted to a PVDF membrane. Immunoblots were blocked with $10 \%$ skimmed milk in TBS followed by incubation with primary antibodies. Horseradish peroxidase-labeled $\mathrm{ECL}^{\mathrm{TM}}$ Anti-mouse $\operatorname{IgG}(1: 2,000-1: 5,000)$ and $\mathrm{ECL}^{\mathrm{TM}}$ Anti-rabbit $\operatorname{IgG}(1: 5,000-1: 20,000)$ from GE Healthcare were used as secondary antibodies and detected using Clarity Max Western ECL Substrate from Bio-Rad Laboratories, Inc. according to the manufacturer's instructions. Expression of $\beta$-actin was used as a loading control. The images were analyzed using Ez-Capture MG (Atto Corporation). The following antibodies were used: Anti-cyclin D1 (cat. no. 2922), anti-cyclin B1 (cat. no. 4135S), anti-E2F transcription factor 1 (E2F-1; cat. no. 3742), anti-cyclin-dependent kinase 1 (CDK1; cat. no. 77055S), anti-GS (cat. no. 3893), anti-phospho-GS (Ser641) (cat. no. 3891), anti-poly (ADP-ribose) polymerase (PARP; cat.no.9542), anti-GSK-3 $\beta$ (cat.no. 12456), anti- $\beta$-actin (cat. no. 12262) from Cell Signaling Technology, Inc.; anti-X-linked inhibitor of apoptosis (XIAP; cat. no. 610716) and anti-Bcl-2 (cat. no. 610538) from BD Biosciences. The dilution ratios of the primary antibodies were 1:250-1:1,000.

$R N A$ extraction and reverse transcription-quantitative $P C R$ $(R T-q P C R)$. ACHN, Caki-1, KRCY and KU19-20 cell lines were treated with 0,25 and $50 \mu \mathrm{M}$ 9-ING-41. Total cellular RNA was extracted using the SV Total RNA Isolation System (Promega Corporation) and the first-strand DNA was synthesized using a cDNA Reverse Transcription kit (Applied Biosystems; Thermo Fisher Scientific, Inc.) following the manufacturer's instructions. qPCR was performed in a 7300 Real-Time PCR System (Applied Biosystems; Thermo Fisher Scientific, Inc.) with 40 cycles of denaturation $\left(95^{\circ} \mathrm{C}\right.$ for $\left.15 \mathrm{sec}\right)$, annealing and elongation $\left(60^{\circ} \mathrm{C}\right.$ for $\left.1 \mathrm{~min}\right)$. Predesigned TaqMan ${ }^{\circledR}$ Gene Expression assays (Applied Biosystems; Thermo Fisher Scientific, Inc.) targeting human Bcl-2 (assay ID, Hs00236808_s1), E2F1 (assay ID, Hs00153451_m1) mRNA were used, and GAPDH (assay ID, Hs02758991_g1) was used as an endogenous control. Each experiment was performed in triplicate wells for each sample in a final reaction volume of $20 \mu 1$ using a TaqMan ${ }^{\circledR}$ Universal PCR Master Mix (Applied Biosystems; Thermo Fisher Scientific, Inc.) according to the manufacturer's protocol. The expression of the target mRNA was quantified relative to that of the GAPDH mRNA using the $2^{-\Delta \Delta \mathrm{Cq}}$ method as previously described (21) and untreated controls were used as a reference.

Cytotoxicity assay. Human peripheral blood mononuclear cells (PBMC) were separated from human blood obtained from healthy volunteers using Lymphocyte Separation Solution (Nacalai Tesque, Inc.). For activation, PBMCs were suspended at a concentration of $2 \times 10^{6}$ cells $/ \mathrm{ml}$ in RPMI- 1640 medium containing $10 \%$ FBS, and recombinant human interleukin 2 (IL-2; cat. no. 0617AFC12; Peprotech, Inc.) was added at a concentration of 2,000 IU/ml. PBMCs were cultured for 3 days at $37^{\circ} \mathrm{C}$ in a $5 \% \mathrm{CO}_{2}$ atmosphere. CytoTox $96^{\circledR}$ Non-radioactive Cytotoxic Assay (Promega Corporation) was used according to the manufacturer's instructions. The CytoTox $96^{\circledR}$ colorimetric assay measures lactate dehydrogenase (LDH), a stable cytosolic enzyme that is released upon cell lysis. Briefly, RCC cells ACHN and Caki-1 and activated PBMCs were added to 

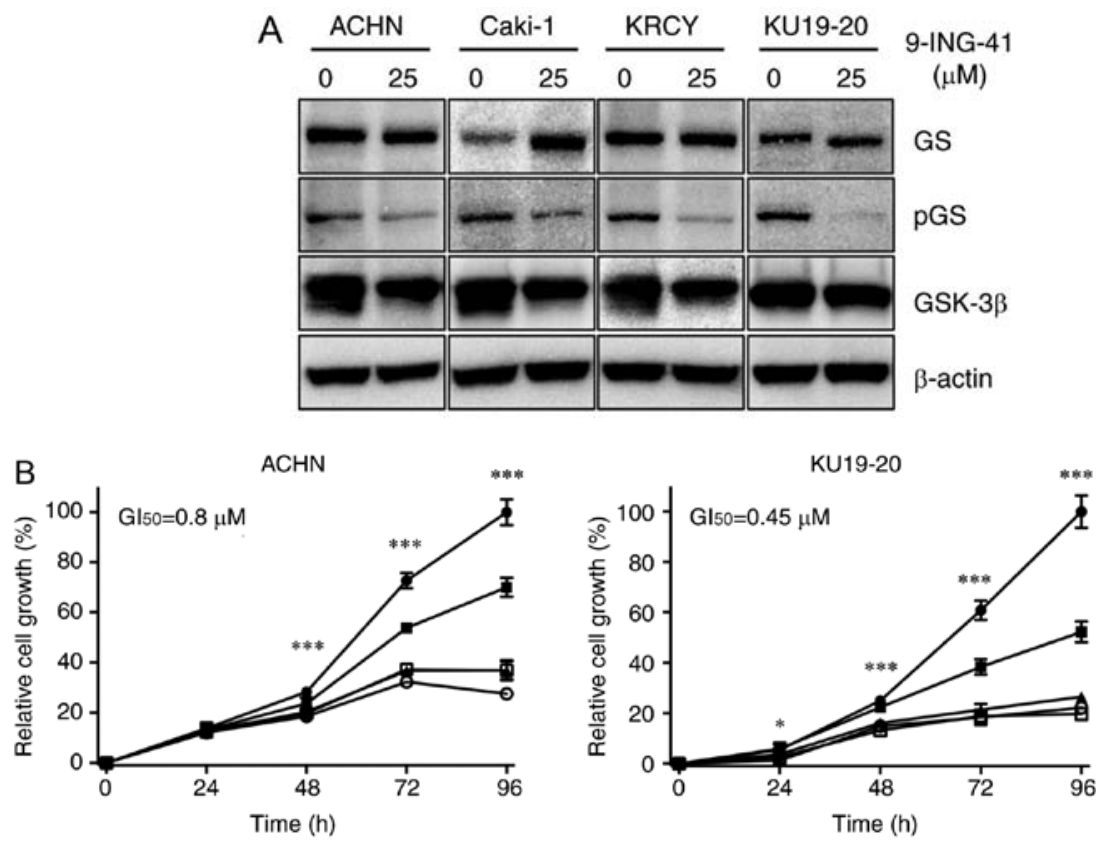

Caki-1

KRCY
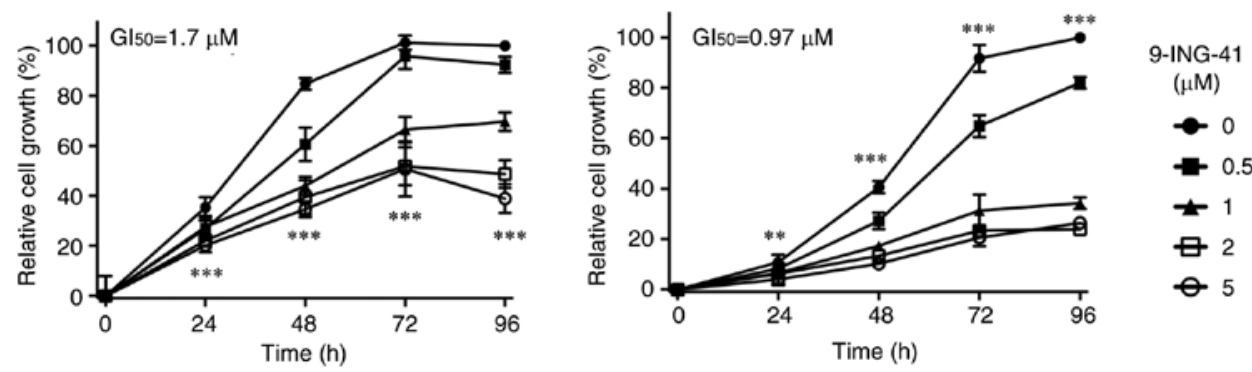

C

ACHN

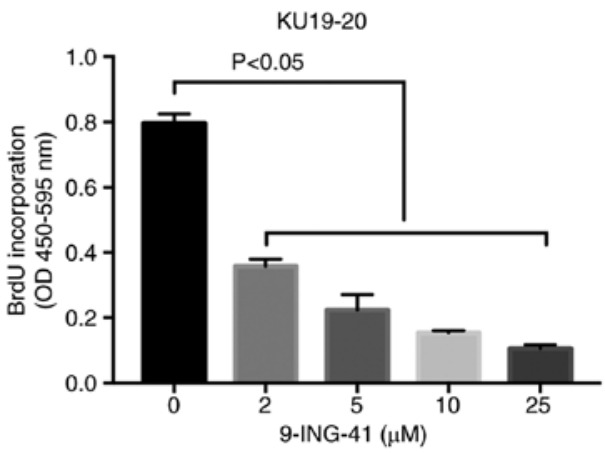

Caki-1

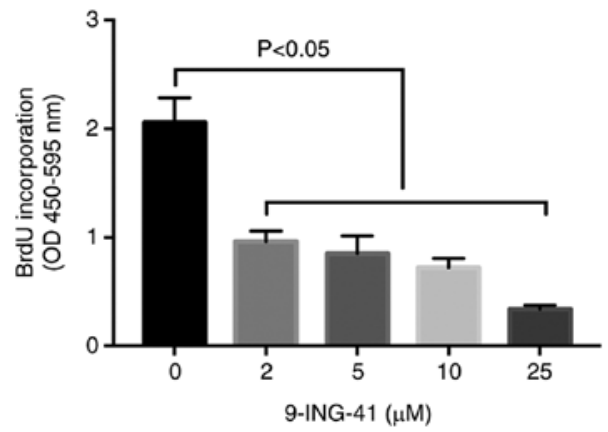

KRCY

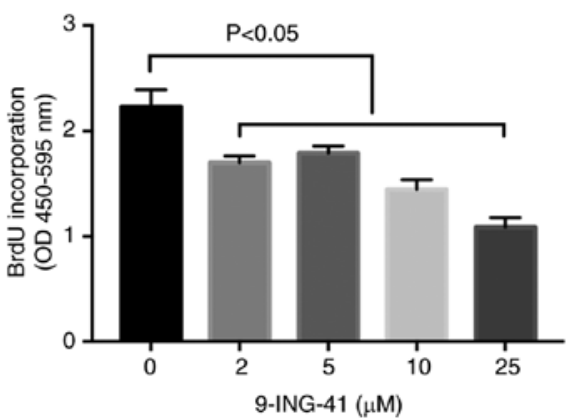

Figure 1. Treatment with 9-ING-41 inhibits the proliferation and survival of RCC cells. (A) RCC cells were treated with the indicated concentrations of 9-ING-41 for $96 \mathrm{~h}$, and protein expression was analyzed by western blotting. (B) Relative cell proliferation was measured by MTS assay in RCC cells treated with the indicated doses of 9-ING-41 for 24, 48, 72 and $96 \mathrm{~h}$. Differences were analyzed by one-way ANOVA. (C) BrdU colorimetric assay was performed in RCC cells treated with diluent (DMSO) or 9-ING-41 at indicated concentrations for $48 \mathrm{~h} .{ }^{*} \mathrm{P}<0.05,{ }^{* *} \mathrm{P}<0.01$ and ${ }^{* * * *} \mathrm{P}<0.001$. RCC, renal cell carcinoma; GS, glycogen synthase; p, phosphorylated; GSK-3 $\beta$, glycogen synthase kinase- $3 \beta$; $\mathrm{GI}_{50}$, concentration that inhibits cell proliferation by $50 \%$; BrdU, 5-bromo-2-deoxyuridine; OD, optical density. 
A
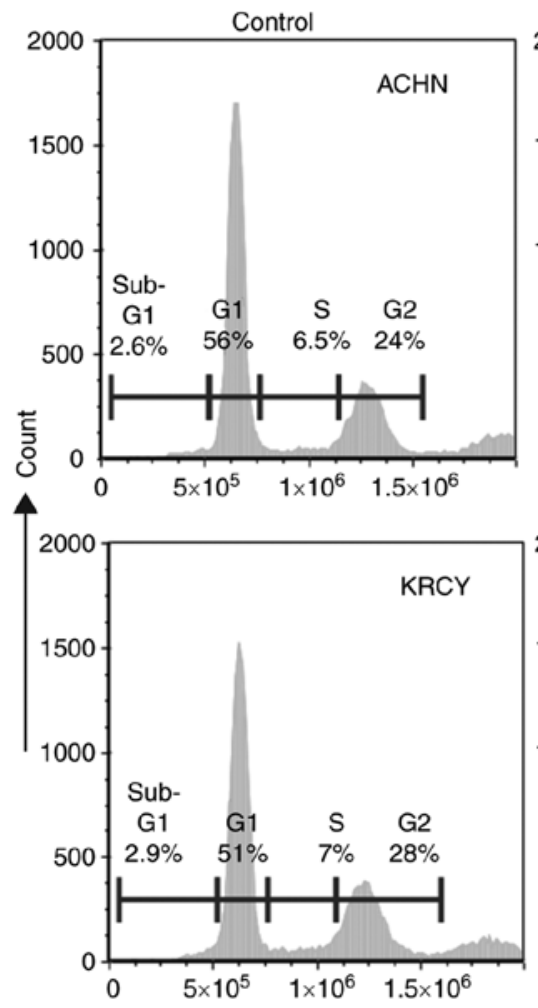
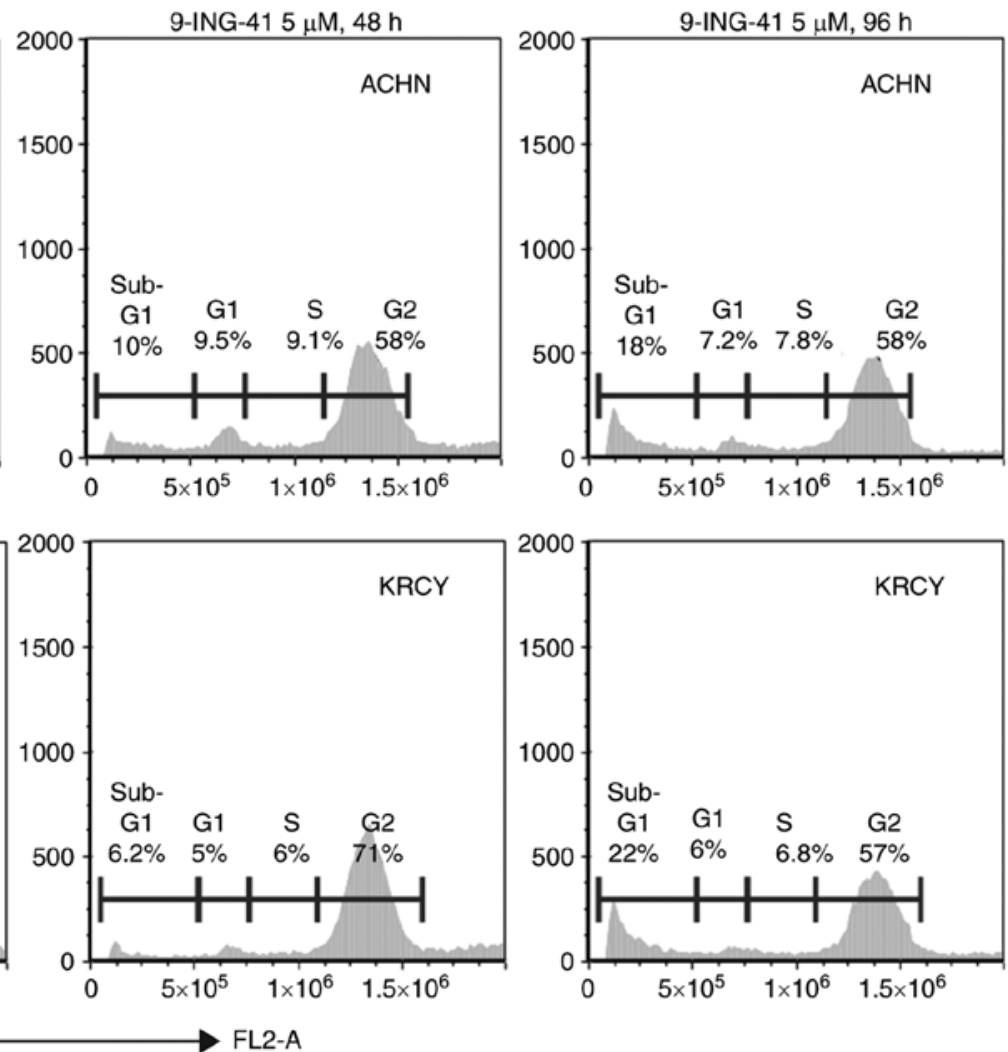
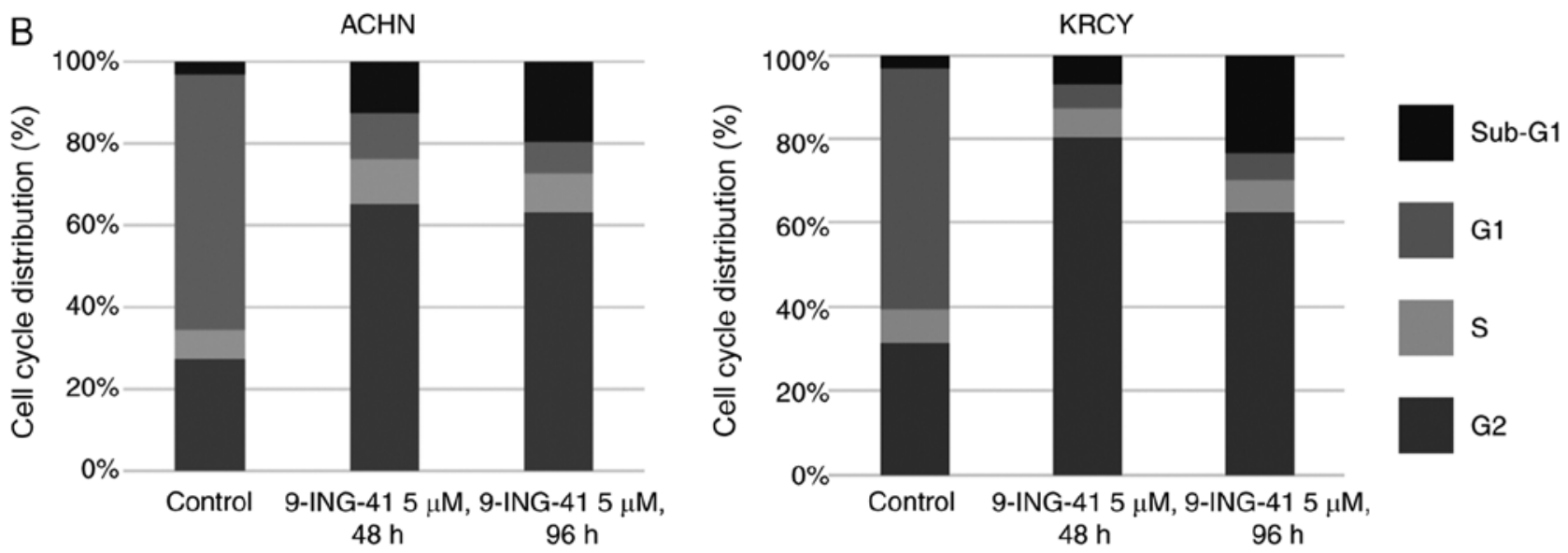

Figure 2. 9-ING-41 induces cell cycle arrest and apoptosis in RCC cells. (A) Flow cytometry was performed in ACHN and KRCY renal cancer cells treated with $5 \mu \mathrm{M}$ 9-ING-41 for 48 and $96 \mathrm{~h}$. (B) Cell cycle distribution and rate of sub- $\mathrm{G}_{1}, \mathrm{G}_{1}, \mathrm{~S}$ and $\mathrm{G}_{2}$ populations are presented following treatment of RCC cells with 9-ING-41 as indicated. RCC, renal cell carcinoma; FL2-A, total cell fluorescence area.

a round-bottom 96-well plate (Corning, NY) and mixed at the lymphocyte to cancer cell ratios between 1:2.5 and 1:80. Following 4-h incubation at $37^{\circ} \mathrm{C}, 50 \mu \mathrm{l}$ of the supernatants were transferred to a fresh 96-well flat-bottom plate (Corning, Inc.), and the absorbance signal was measured at $490 \mathrm{~nm}$ using an iMark ${ }^{\mathrm{TM}}$ Microplate Reader. Experiments were performed in triplicate.

Statistical analysis. Continuous variables are presented as the mean \pm SD. All continuous variables in this study met the criteria for a normal distribution and were assumed to be parametric. Data were analyzed using one-way ANOVA with Dunnett's test for multiple comparisons. Statistical analysis was performed using GraphPad Prism 7 software (GraphPad
Software, Inc.). $\mathrm{P}<0.05$ was considered to indicate a statistically significant difference.

\section{Results}

Treatment with 9-ING-41 inhibits the proliferation of renal cancer cells. Immunoblotting was used to determine GSK-3 $\beta$ expression in ACHN, Caki-1, KRCY and KU19-20 RCC cell lines (Fig. 1A). Treatment with $9-\mathrm{ING}-41$ resulted in reduced GSK-3 $\beta$ activity in all RCC cell lines, indicated by the decreased expression of phospho-GS, a downstream target of GSK-3 $\beta$, compared with control cells treated with DMSO (Fig. 1A). The results of the MTS assay demonstrated that treatment with 9-ING-41 decreased the proliferation of RCC 


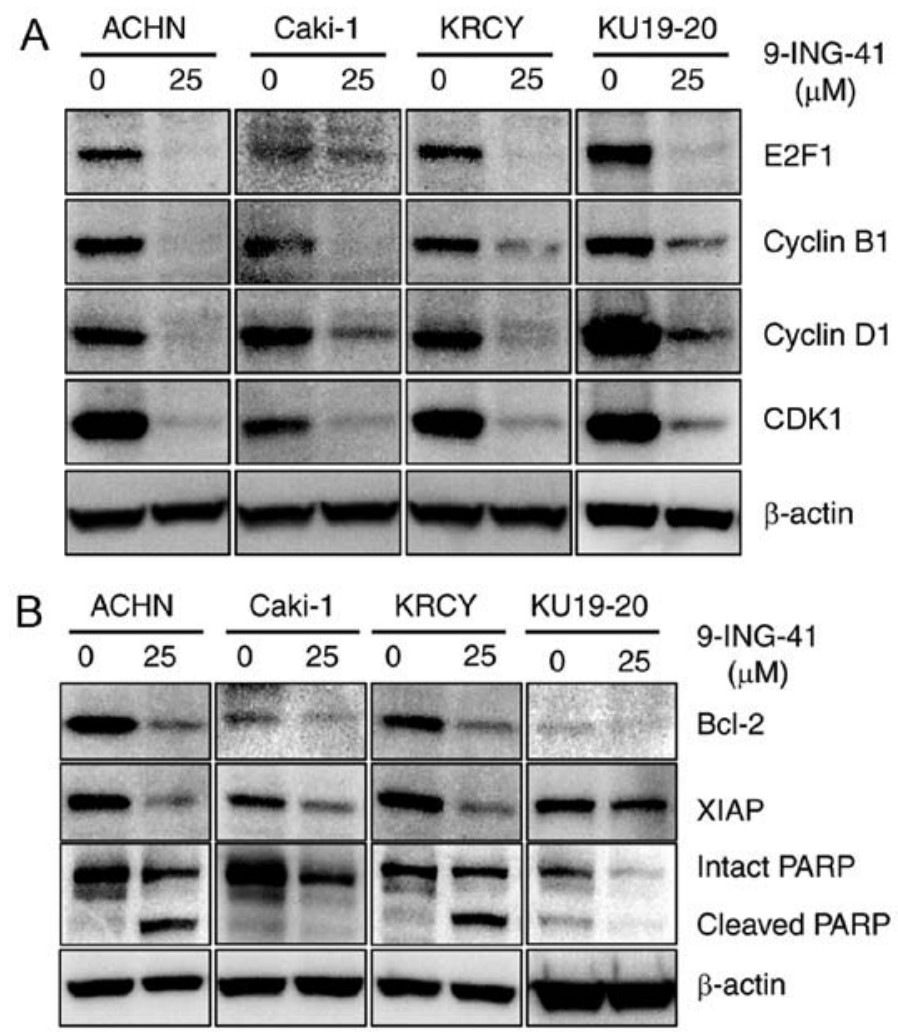

C

$\mathrm{BCl}-2$

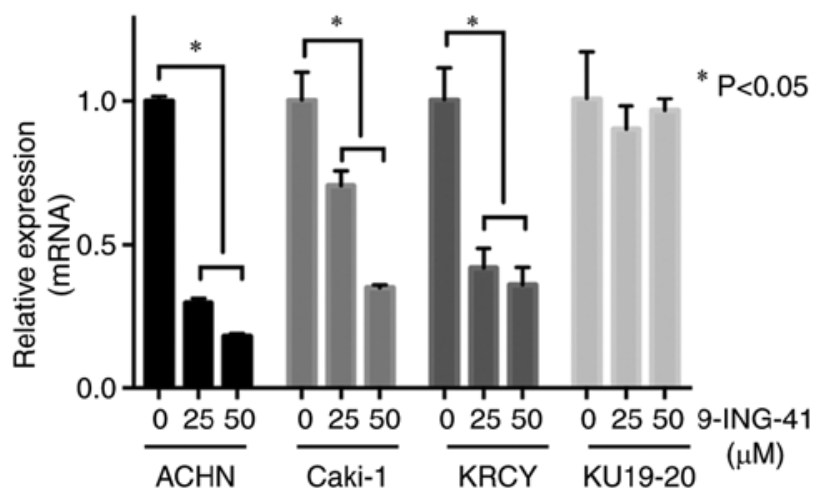

E2F1

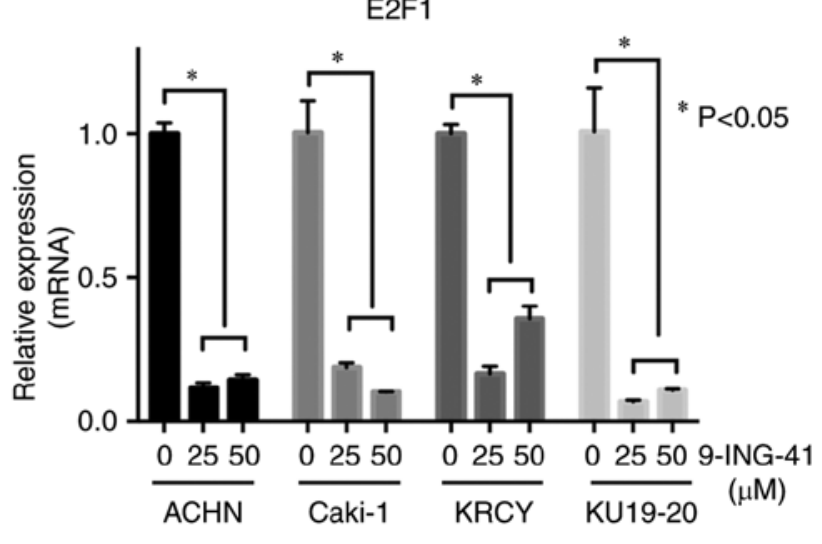

Figure 3. Treatment with 9-ING-41 suppresses the expression of cyclin-dependent kinases and anti-apoptotic proteins in RCC cells. (A and B) RCC cells were treated with the indicated concentrations of 9-ING-41 for $96 \mathrm{~h}$, and protein expression was analyzed by western blotting. (C) Reverse transcription-quantitative PCR was performed in RCC cells following treatment with the indicated doses of 9-ING-41 for $72 \mathrm{~h}$. Gene expression of Bcl-2 and E2F-1 was significantly decreased in cells treated with 9-ING-41 compared with the control cells. "P<0.05. RCC, renal cell carcinoma; E2F-1, E2F transcription factor 1; CDK1, cell cycle controller 2; XIAP, X-linked inhibitor of apoptosis; PARP, poly (ADP-ribose) polymerase.

cells at low micromolar concentrations in a dose-dependent manner with a $\mathrm{GI}_{50}$ range of 0.5-1.7 $\mu \mathrm{M}$ (Fig. 1B). The results of the BrdU incorporation assay confirmed that treatment with 9-ING-41 inhibited the proliferation of RCC cells compared with the respective control groups (Fig. 1C).

Treatment with 9-ING-41 induces cell cycle arrest and apoptosis in renal cancer cells. PI-fluorescence-activated cell sorting revealed that treatment with 9-ING-41 for $48 \mathrm{~h}$ induced cell cycle arrest at the $\mathrm{G}_{2}$ phase, and treatment for $96 \mathrm{~h}$ induced cell cycle arrest with an increased sub- $\mathrm{G}_{1}$ cell population, which is an indicator of apoptosis, in ACHN and KRCY cells compared with the control groups (Fig. 2A and B). Mechanistically, the expression of Cyclin B1 and CDK1 proteins, which serve an important role in the transition from $\mathrm{G}_{2}$ to $\mathrm{M}$ phase, was decreased following treatment with 9-ING-41 (Fig. 3A). In addition, the expression of E2F-1 and cyclin D1 proteins, which serve a crucial role in the cell cycle, was decreased following treatment with 9-ING-41 (Fig. 3A). Treatment with 9-ING-41 decreased the expression of antiapoptotic proteins, Bcl-2 and XIAP, leading to an increase in apoptosis indicated by PARP cleavage, which is a marker of apoptosis (Fig. 3B). However, the immunoblotting results also indicated that Bcl-2 was scarcely expressed in KU19-20. RT-qPCR results demonstrated decreased Bcl-2 and E2F1 mRNA expression in RCC cells treated with 9-ING-41 compared with the controls, with the exception of $\mathrm{Bcl}-2$ in KU19-20 (Fig. 3C). 


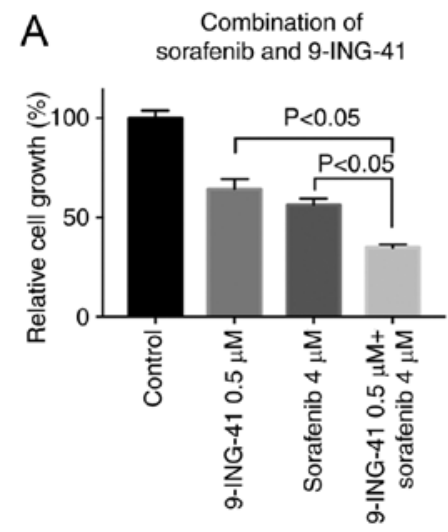

Combination of pazopanib and 9-ING-41
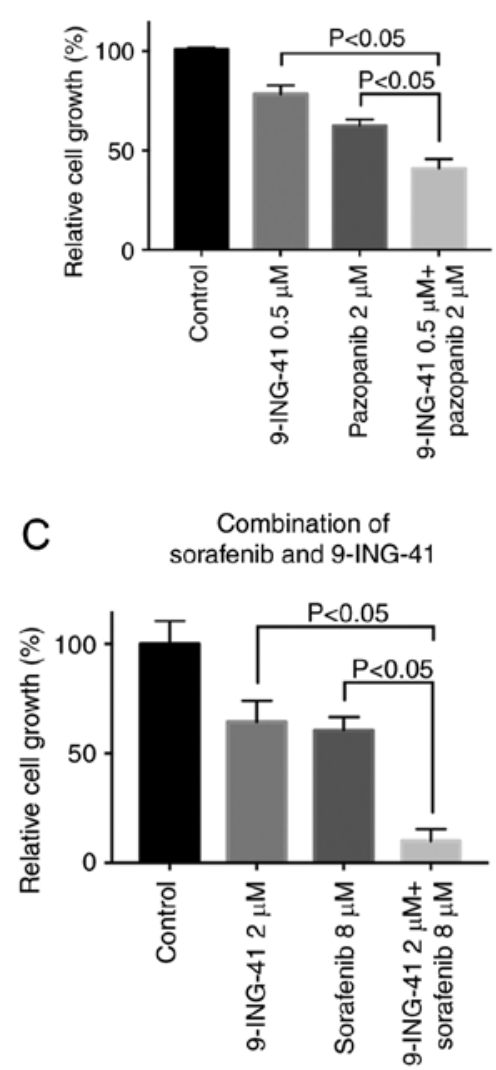

Combination of pazopanib and 9-ING-41

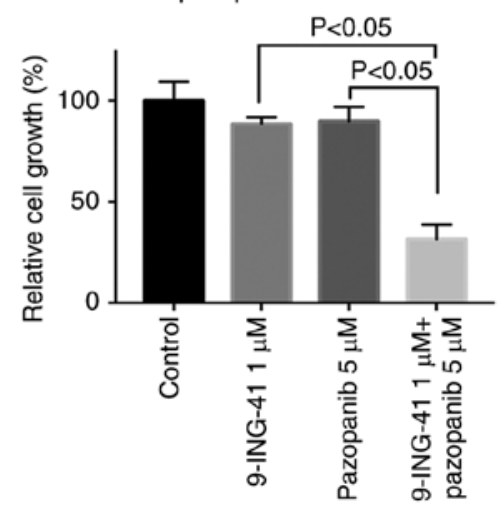

Combination of sunitinib and 9-ING-41

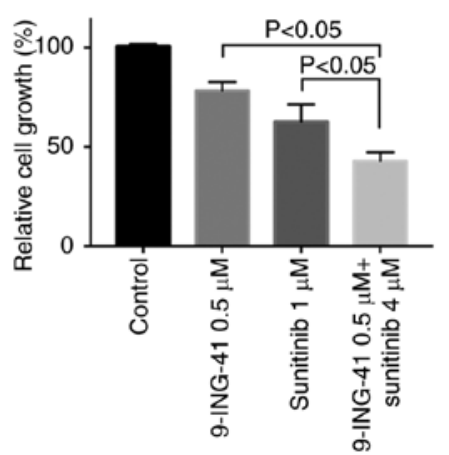

Combination of cabozantinib and 9-ING-41

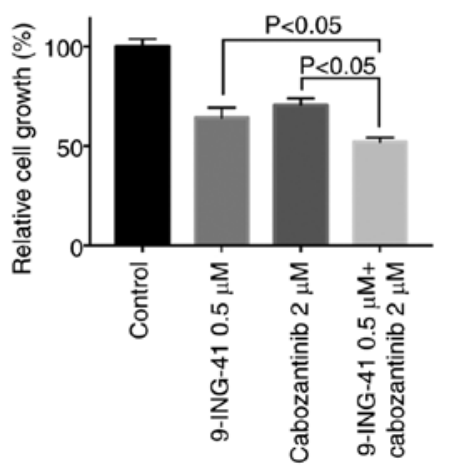

Combination of sunitinib and 9-ING-41

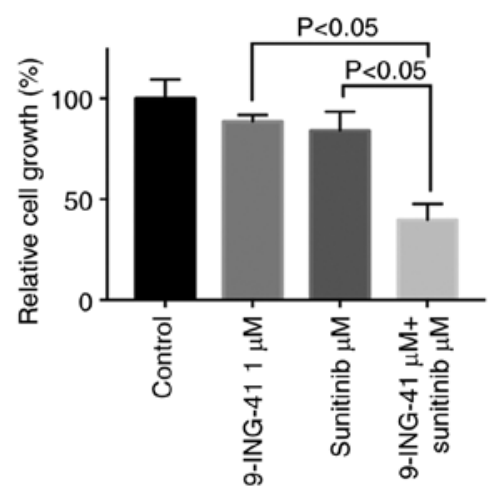

Combination of cabozantinib and 9-ING-41

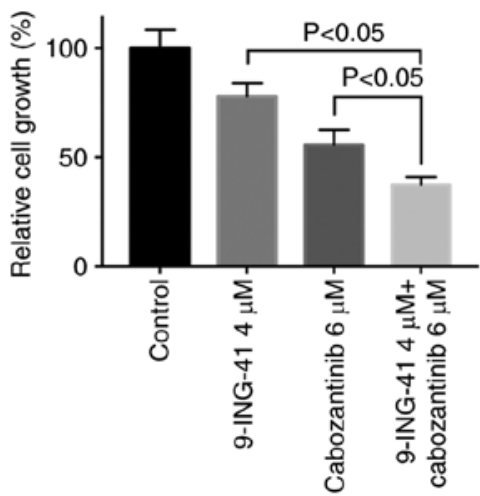

B Combination of

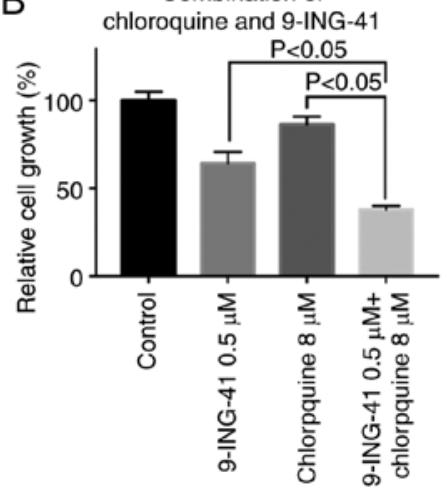

Combination of bafilomycin and 9-ING-41

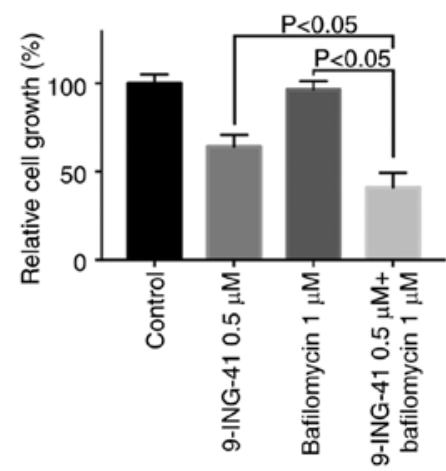

D Combination of chloroquine and 9-ING-41

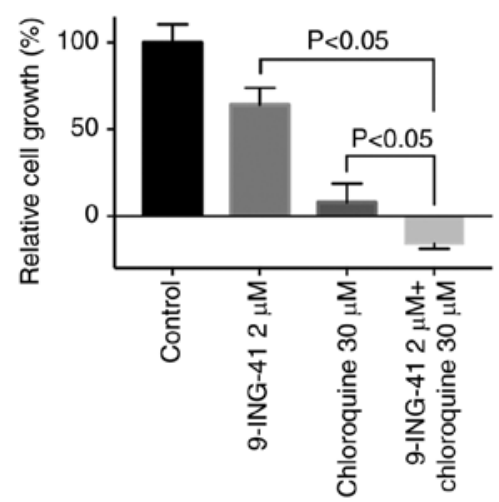

Combination of bafilomycin and 9-ING-41

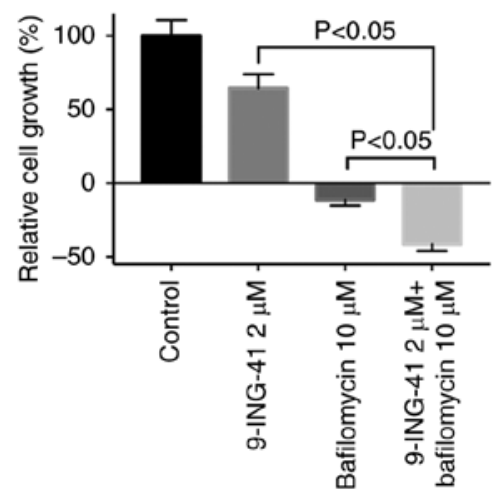

Figure 4. Pharmacological inhibition of GSK-3 with 9-ING-41 potentiates the effect of anticancer therapeutics in RCC cells. Relative cell proliferation was measured by MTS assay in RCC cell lines (A and B) ACHN and (C and D) Caki-1 treated with 9-ING-41 in combination with (A and C) targeted therapeutics (sorafenib, sunitinib, pazopanib and cabozantinib) or (B and D) autophagy inhibitors (chloroquine and bafilomycin) for $72 \mathrm{~h}$ as indicated. RCC, renal cell carcinoma. 

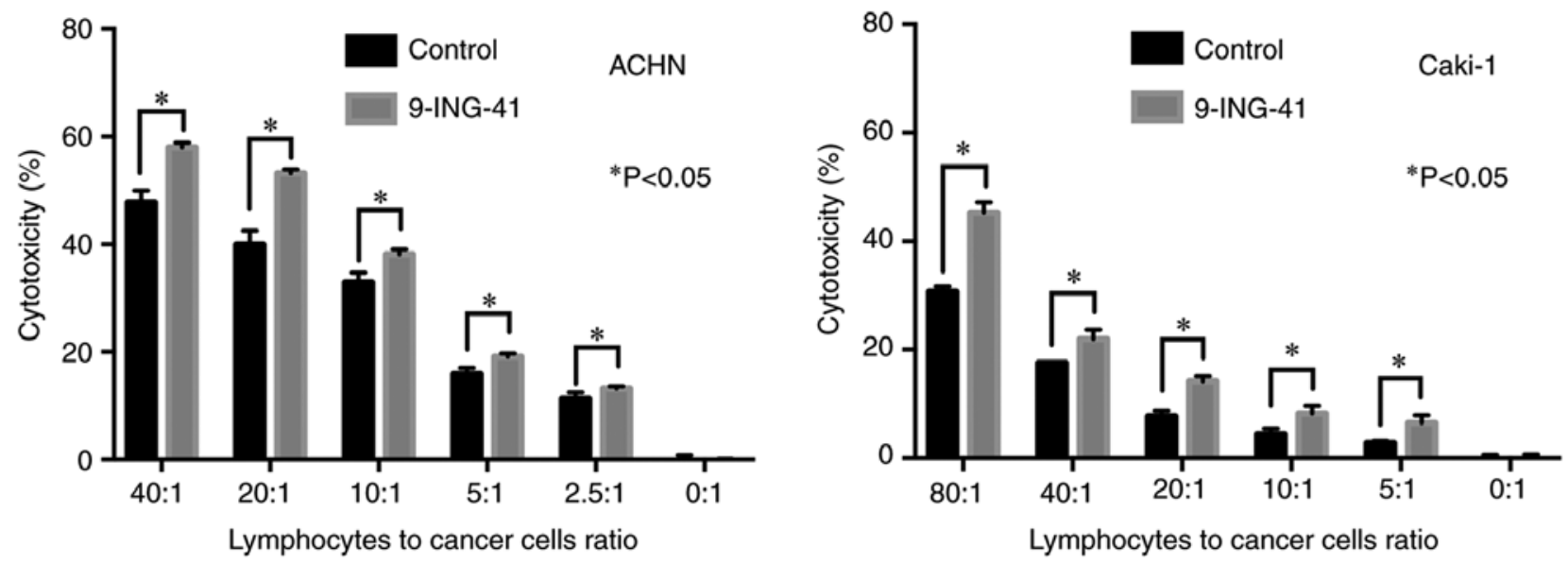

Figure 5. Treatment with 9-ING-41 sensitizes renal cancer cells to the cytotoxic effects of human immune cells. ACHN and Caki-1 renal cancer cells were treated with 9-ING-41 as indicated, harvested and mixed with activated human immune cells. Lactate dehydrogenase activity of the supernatants was measured and cytotoxicity was calculated. The effector:target ratio indicates the proportion of immune to cancer cells. ${ }^{*} \mathrm{P}<0.05$.

9-ING-41 potentiates the antitumor effects of targeted therapeutics and autophagy inhibitors in RCC cells. Using RCC cell lines, the effects of 9-ING-41 in combination with first- and second-line RCC targeted therapeutics sunitinib, pazopanib, sorafenib and cabozantinib were investigated (Figs. 4A, C and S1). For combination experiments, a minimally effective and clinically relevant concentration of $0.5-2 \mu \mathrm{M}$ 9-ING-41 was used for ACHN $\left(\mathrm{GI}_{50}=0.8 \mu \mathrm{M}\right)$, Caki-1 $\left(\mathrm{GI}_{50}=1.7 \mu \mathrm{M}\right)$, $\operatorname{KRCY}\left(\mathrm{GI}_{50}=1 \mu \mathrm{M}\right)$ and $\mathrm{KU} 19-20\left(\mathrm{GI}_{50}=0.5 \mu \mathrm{M}\right)$ cells. The results of the MTS assay demonstrated that 9-ING-41 potentiated the antitumor effects of sorafenib $(\mathrm{P}<0.05)$, cabozantinib $(\mathrm{P}<0.05)$, sunitinib $(\mathrm{P}<0.05)$ and pazopanib $(\mathrm{P}<0.05)$ in $\mathrm{RCC}$ cells (Figs. 4A, C and S1).

To test the hypothesis that an autophagy inhibitor may potentiate the antitumor effects of 9-ING-41, RCC cells were treated with a combination of 9-ING-41 (0.5-2 $\mu \mathrm{M})$ and the autophagy inhibitors chloroquine (8-30 $\mu \mathrm{M})$ and bafilomycin (1-10 $\mu \mathrm{M})$. The results of the MTS assay revealed that the antitumor effect of 9-ING-41 was significantly increased when 9-ING-41 was combined with chloroquine $(\mathrm{P}<0.05)$ or bafilomycin $(\mathrm{P}<0.05)$ compared with single treatments in $\mathrm{RCC}$ cells (Figs. 4B, D and S1).

Treatment with 9-ING-41 potentiates the antitumor effects of immune cells in RCC. To investigate whether GSK-3 inhibition affects the antitumor effects of human immune cells in RCC cell lines, ACHN and Caki-1 renal cancer cells were treated with 9-ING-41 for $72 \mathrm{~h}$, and then mixed with activated PBMCs at various ratios. LDH activity of the supernatant was measured to evaluate the cytotoxic effects (Fig. 5). The results demonstrated that treatment with $9-\mathrm{ING}-41$ significantly increased the cytotoxic effects of activated PBMCs in representative RCC cell lines ACHN and Caki-1 compared with control cells treated with DMSO (Fig. 5).

\section{Discussion}

GSK-3 $\beta$ has been identified as a potential therapeutic target in human $\operatorname{RCC}(14,20)$. The results of our previous study identified GSK-3 as a positive regulator of RCC cell survival, proliferation and chemoresistance (14). Since the two isoforms of GSK-3, $\alpha$ and $\beta$, are $98 \%$ homologous in the kinase domain, the majority of known competitive inhibitors of GSK-3 inhibit both isoforms, and should thus be referred to as GSK-3 inhibitors rather than GSK-3 $\beta$ inhibitors (22). Previous studies have demonstrated that treatment with 9-ING-41, a clinical stage GSK-3 $\beta$ inhibitor, at clinically relevant concentrations of $0.5-2 \mu \mathrm{M}$ suppresses the viability of neuroblastoma, ovarian, pancreatic and breast cancer cells in vitro $(15,16,18,19)$. Pharmacokinetic studies have demonstrated that $9-\mathrm{ING}-41(20 \mathrm{mg} / \mathrm{kg}$ at $30 \mathrm{~min}$ after intravenous administration) could reach mouse plasma and brain concentration of $\sim 7 \mu \mathrm{M}$ and $44 \mu \mathrm{M}$, respectively (17). The results of the present study demonstrated that treatment with $0.5-2 \mu \mathrm{M}$ 9-ING-41 suppressed the viability of renal cancer cells. These results were supported by another study, which demonstrated that treatment with ARA-014418, a toolkit GSK-3 inhibitor, resulted in a significant decrease of antiapoptotic proteins Bcl-2 and XIAP and induction of apoptosis in RCC cells (14). Consistent with the previous report by Pal et al (20), the results of the present study indicated that treatment with 9-ING-41 induced cell cycle arrest in RCC cells.

Resistance to the current standard treatments in metastatic RCC has led to a poor prognosis for patients with this disease (2). NF- $\kappa \mathrm{B}$-mediated drug resistance results in $\mathrm{RCC}$ progression and recurrence (23). Inhibition of GSK-3 $\beta$, a positive regulator of NF- $\kappa \mathrm{B}$-mediated survival in cancer cells $(24,25)$, may be an effective therapeutic approach to overcome RCC resistance to antitumor drugs. Recently, treatment with the GSK-3 inhibitor 9-ING-41 has been demonstrated to overcome the resistance to chemotherapeutic drugs in models of breast cancer (19), glioblastoma (17) and neuroblastoma (18). Another study has reported that ARA-014418 enhances the antitumor effect of sorafenib in RCC cells (26). The results of the present study demonstrated that 9-ING-41 potentiated the antitumor effects of the first- and second-line RCC targeted therapeutics sunitinib, pazopanib, sorafenib and cabozantinib. These results provided a rationale for the combination of 9-ING-41 with targeted therapeutics for effective treatment of RCC. 
Although the role of autophagy in cancer is complex and context-dependent, autophagy has been suggested as a potential mechanism of evading apoptosis in cancer cells (27). A number of antitumor therapies have been identified to induce autophagy in human cancer cells (28-30). Whether autophagy induced by antitumor therapy contributes to apoptosis of cancer cells or represents a mechanism of resistance to therapy-mediated apoptosis remains unclear. An increase of intracellular glucose storage and induction of autophagy have been demonstrated in 9-ING-41-treated renal cancer cells (20). Inhibition of GSK-3 triggers an autophagic response in prostate (31), pancreatic (32) and renal (20) cancer. Pal et al (20) have demonstrated that GSK-3 inhibition by 9-ING-41 affects energy homeostasis and triggers a pro-survival autophagic response in renal cancer cells. In the present study, 9-ING-41 increased the antitumor effects of the autophagy inhibitors chloroquine and bafilomycin in RCC cells. These results are in agreement with previously published work demonstrating that the inhibition of autophagy by bafilomycin sensitized pancreatic cancer cells to GSK-3 inhibition-induced apoptosis (32). The results of the present study support the hypothesis that autophagy-mediated resistance to 9 -ING-41 therapy may be overcome by combining 9-ING-41 with autophagy inhibitors in human RCC.

Historically, the treatment of metastatic RCC included immune-modulating therapies, such as interferon $\alpha$ and IL-2 (33). However, these therapies exhibit significant toxicity and low efficacy (33). Since the introduction of targeted therapy, targeted tyrosine kinase inhibitors and vascular endothelial growth factor have become the standard treatments for advanced RCC (2). The development of immune checkpoint inhibitors for RCC treatment has further improved treatment outcomes for patients with advanced RCC (2). Results from clinical trials have demonstrated that immune checkpoint inhibitors improved overall survival in treatment-naïve or previously treated metastatic RCC $(34,35)$. In the present study, treatment with 9-ING-41 significantly increased the cytotoxic effect of human immune cells added to RCC cell lines. These results suggested 9-ING-41-treatment increased RCC cells vulnerability to activated human immune cells. Further experiments using autologous models are being performed in our laboratory to explore the molecular mechanisms of this phenomenon.

The results of the present study support the hypothesis that treatment with the specific small molecule GSK-3 $\beta$ inhibitor 9-ING-41 may potentiate the antitumor immune response in patients with RCC. 9-ING-41 has exhibited significant clinical activity in patients with advanced cancer (clinical trial no. NCT03678883). These results provide a compelling rationale for the inclusion of patients with advanced renal cancer in studies of 9-ING-41, both as a single agent and in combination with current standard therapies.

\section{Acknowledgements}

Not applicable.

\section{Funding}

The present study was supported by research grant from the Department of Urology, Niigata University (Niigata City, Japan).

\section{Availability of data and materials}

All data generated or analyzed during this study are included in this published article.

\section{Authors' contributions}

TA, VB, AU and YT conceived and designed the study. TA, HK, AK, VB, MT, AU and YT developed the methodology. $\mathrm{TA}, \mathrm{HK}$ and $\mathrm{AK}$ performed the experiments. TA, VB, AU and YT analyzed and interpreted the data. TA, HK, AK, VB, MT, DS, AM, FG, AU and YT wrote, reviewed and/or revised the manuscript. DS, AM, FG and YT provided administrative, technical, or material support. YT, TA and VB supervised the study. All authors read and approved the final manuscript.

\section{Ethics approval and consent to participate}

This study was approved by Niigata University Ethical Committee (approval no. 2620), and informed consent was obtained from healthy volunteers.

\section{Patient consent for publication}

Not applicable.

\section{Competing interests}

9-ING-41 has been licensed to Actuate Therapeutics, Inc. Andrew Mazar, Andrey Ugolkov, Daniel Schmitt and Francis Giles hold an equity interest in Actuate Therapeutics, Inc.

\section{References}

1. Siegel RL, Miller KD and Jemal A: Cancer statistics, 2017. CA Cancer J Clin 67: 7-30, 2017.

2. Rodriguez-Vida A, Hutson TE, Bellmunt $J$ and Strijbos MH: New treatment options for metastatic renal cell carcinoma. ESMO Open 2: e000185, 2017.

3. Motzer RJ, Hutson TE, Cella D, Reeves J, Hawkins R, Guo J, Nathan P, Staehler M, de Souza P, Merchan JR, et al: Pazopanib versus sunitinib in metastatic renal-cell carcinoma. N Engl J Med 369: 722-731, 2013.

4. Motzer RJ, Hutson TE, Tomczak P, Michaelson MD, Bukowski RM, Rixe O, Oudard S, Negrier S, Szczylik C, Kim ST, et al: Sunitinib versus interferon alfa in metastatic renal-cell carcinoma. N Engl J Med 356: 115-124, 2007.

5. Sternberg CN, Davis ID, Mardiak J, Szczylik C, Lee E, Wagstaff J, Barrios CH, Salman P, Gladkov OA, Kavina A, et al: Pazopanib in locally advanced or metastatic renal cell carcinoma: Results of a randomized phase III trial. J Clin Oncol 28: 1061-1068, 2010.

6. Eldar-Finkelman H: Glycogen synthase kinase 3: An emerging therapeutic target. Trends Mol Med 8: 126-132, 2002.

7. Schlender KK, Beebe SJ, Willey JC, Lutz SA and Reimann EM: Isolation and characterization of cyclic AMP-independent glycogen synthase kinase from rat skeletal muscle. Biochim Biophys Acta 615: 324-340, 1980.

8. Nagini S, Sophia J and Mishra R: Glycogen synthase kinases: Moonlighting proteins with theranostic potential in cancer. Semin Cancer Biol 56: 25-36, 2019.

9. de Groot RP, Auwerx J, Bourouis M and Sassone-Corsi P: Negative regulation of Jun/AP-1: Conserved function of glycogen synthase kinase 3 and the drosophila kinase shaggy. Oncogene 8: 841-847, 1993.

10. Sears R, Nuckolls F, Haura E, Taya Y, Tamai K and Nevins JR: Multiple Ras-dependent phosphorylation pathways regulate Myc protein stability. Genes Dev 14: 2501-2514, 2000. 
11. Diehl JA, Cheng M, Roussel MF and Sherr CJ: Glycogen synthase kinase-3beta regulates cyclin D1 proteolysis and subcellular localization. Genes Dev 12: 3499-3511, 1998.

12. Rubinfeld B, Albert I, Porfiri E, Fiol C, Munemitsu S and Polakis P: Binding of GSK3beta to the APC-beta-catenin complex and regulation of complex assembly. Science 272: 1023-1026, 1996.

13. Walz A, Ugolkov A, Chandra S, Kozikowski A, Carneiro BA, O'Halloran TV, Giles FJ, Billadeau DD and Mazar AP: Molecular pathways: Revisiting glycogen synthase kinase- $3 \beta$ as a target for the treatment of cancer. Clin Cancer Res 23: 1891-1897, 2017.

14. Bilim V, Ougolkov A, Yuuki K, Naito S, Kawazoe H, Muto A, Oya M, Billadeau D, Motoyama T and Tomita Y: Glycogen synthase kinase-3: A new therapeutic target in renal cell carcinoma. Br J Cancer 101: 2005-2014, 2009.

15. Hilliard TS, Gaisina IN, Muehlbauer AG, Gaisin AM, Gallier F and Burdette JE: Glycogen synthase kinase $3 \beta$ inhibitors induce apoptosis in ovarian cancer cells and inhibit in-vivo tumor growth. Anticancer Drugs 22: 978-985, 2011.

16. Gaisina IN, Gallier F, Ougolkov AV, Kim KH, Kurome T, Guo S, Holzle D, Luchini DN, Blond SY, Billadeau DD and Kozikowski AP: From a natural product lead to the identification of potent and selective benzofuran-3-yl-(indol-3-yl)maleimides as glycogen synthase kinase 3beta inhibitors that suppress proliferation and survival of pancreatic cancer cells. J Med Chem 52: 1853-1863, 2009.

17. Ugolkov A, Qiang W, Bondarenko G, Procissi D, Gaisina I, James CD, Chandler J, Kozikowski A, Gunosewoyo H, O'Halloran T, et al: Combination treatment with the GSK-3 inhibitor 9-ING-41 and CCNU cures orthotopic chemoresistant glioblastoma in patient-derived xenograft models. Transl Oncol 10: 669-678, 2017.

18. Ugolkov AV, Bondarenko GI, Dubrovskyi O, Berbegall AP, Navarro S, Noguera R, O'Halloran TV, Hendrix MJ, Giles FJ and Mazar AP: 9-ING-41, a small-molecule glycogen synthase kinase-3 inhibitor, is active in neuroblastoma. Anticancer Drugs 29: 717-724, 2018.

19. Ugolkov A, Gaisina I, Zhang JS, Billadeau DD, White K, Kozikowski A, Jain S, Cristofanilli M, Giles F, O'Halloran T, et al: GSK-3 inhibition overcomes chemoresistance in human breas cancer. Cancer Lett 380: 384-392, 2016.

20. Pal K, Cao Y, Gaisina IN, Bhattacharya S, Dutta SK, Wang E, Gunosewoyo H, Kozikowski AP, Billadeau DD and Mukhopadhyay D: Inhibition of GSK-3 induces differentiation and impaired glucose metabolism in renal cancer. Mol Cancer Ther 13: 285-296, 2014

21. Schmittgen TD and Livak KJ: Analyzing real-time PCR data by the comparative C(T) method. Nat Protoc 3: 1101-1108, 2008.

22. Cormier KW and Woodgett JR: Recent advances in understanding the cellular roles of GSK-3. F1000Res 6: 2017.

23. Morais C, Gobe G, Johnson DW and Healy $\mathrm{H}$ : The emerging role of nuclear factor kappa B in renal cell carcinoma. Int J Biochem Cell Biol 43: 1537-1549, 2011.
24. Ougolkov AV, Bone ND, Fernandez-Zapico ME, Kay NE and Billadeau DD: Inhibition of glycogen synthase kinase-3 activity leads to epigenetic silencing of nuclear factor kappaB target genes and induction of apoptosis in chronic lymphocytic leukemia B cells. Blood 110: 735-742, 2007.

25. Ougolkov AV, Fernandez-Zapico ME, Savoy DN, Urrutia RA and Billadeau DD: Glycogen synthase kinase-3beta participates in nuclear factor kappaB-mediated gene transcription and cell survival in pancreatic cancer cells. Cancer Res 65: 2076-2081, 2005.

26. Kawazoe H, Bilim VN, Ugolkov AV, Yuuki K, Naito S, Nagaoka A, Kato T and Tomita Y: GSK-3 inhibition in vitro and in vivo enhances antitumor effect of sorafenib in renal cell carcinoma (RCC). Biochem Biophys Res Commun 423: 490-495, 2012.

27. Li YJ, Lei YH, Yao N, Wang CR, Hu N, Ye WC, Zhang DM and Chen ZS: Autophagy and multidrug resistance in cancer. Chin J Cancer 36: 52, 2017.

28. Abdel-Mohsen MA, Ahmed OA and El-Kerm YM: BRCA1 gene mutations and influence of chemotherapy on autophagy and apoptotic mechanisms in Egyptian breast cancer patients. Asian Pac J Cancer Prev 17: 1285-1292, 2016.

29. Park JM, Huang S, Wu TT, Foster NR and Sinicrope FA: Prognostic impact of Beclin 1, p62/sequestosome 1 and LC3 protein expression in colon carcinomas from patients receiving 5 -fluorouracil as adjuvant chemotherapy. Cancer Biol Ther 14 100-107, 2013.

30. Gao S, Yang XJ, Zhang WG, Ji YW and Pan Q: Mechanism of thalidomide to enhance cytotoxicity of temozolomide in U251-MG glioma cells in vitro. Chin Med J (Engl) 122: 1260-1266, 2009.

31. Sun A, Li C, Chen R, Huang Y, Chen Q, Cui X, Liu H, Thrasher JB and Li B: GSK-3 $\beta$ controls autophagy by modulating LKB1-AMPK pathway in prostate cancer cells. Prostate 76: 172-183, 2016.

32. Marchand B, Arsenault D, Raymond-Fleury A, Boisvert FM and Boucher MJ: Glycogen synthase kinase-3 (GSK3) inhibition induces prosurvival autophagic signals in human pancreatic cancer cells. J Biol Chem 290: 5592-5605, 2015.

33. Hsieh JJ, Purdue MP, Signoretti S, Swanton C, Albiges L, Schmidinger M, Heng DY, Larkin J and Ficarra V: Renal cell carcinoma. Nat Rev Dis Primers 3: 17009, 2017.

34. Motzer RJ, Tannir NM, McDermott DF, Arén Frontera O, Melichar B, Choueiri TK, Plimack ER, Barthélémy P, Porta C, George $\mathrm{S}$, et al: Nivolumab plus ipilimumab versus sunitinib in advanced renal-cell carcinoma. N Engl J Med 378: 1277-1290, 2018.

35. Motzer RJ, Escudier B, McDermott DF, George S, Hammers HJ, Srinivas S, Tykodi SS, Sosman JA, Procopio G, Plimack ER, et al: Nivolumab versus everolimus in advanced renal-cell carcinoma. N Engl J Med 373: 1803-1813, 2015.

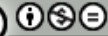

This work is licensed under a Creative Commons Attribution-NonCommercial-NoDerivatives 4.0 International (CC BY-NC-ND 4.0) License. 